\title{
Effects of Hydrophobic-Spot Periphery and Subcooling on Nucleate Pool Boiling from a Mixed-Wettability Surface*
}

\author{
Bambang Joko SUROTO**,***, Masahiro TASHIRO**, Sana HIRABAYASHI**, \\ Sumitomo HIDAKA**, Masamichi $\mathrm{KOHNO}^{* *, * * * *, * * * * *}$ \\ and Yasuyuki TAKATA $* *, * * * *, * * * * *$ \\ **Department of Mechanical Engineering, Kyushu University, Japan \\ E-mail: laks102@yahoo.com \\ ***Department of Physics, Faculty Mathematic and Natural Science, Lampung University, Jl. Prof. \\ Sumantri Brojonegoro No.1, GedongMeneng, Bandar Lampung 35145, Indonesia \\ ****International Institute for Carbon-Neutral Energy Research (WPI-I2CNER), Kyushu University, 744 \\ Motooka, Nishi-ku, Fukuoka 819-0395, Japan \\ ${ }^{* * \star \star *}$ CREST, Japan Science and Technology Agency
}

\begin{abstract}
The effect of subcooling and length of hydrophobic-spot periphery on nucleate pool boiling heat transfer from $\mathrm{TiO}_{2}$-coated surface with and without PTFE (polyetatafluoroethylene) hydrophobic circle spots at intermediate heat flux has been examined. The experiments are performed with liquid subcooling ranging from $0-20 \mathrm{~K}$ and heat transfer block used were $\mathrm{TiO}_{2}$-coated copper block with a PTFE hydrophobic circle spot with various diameters with total area of PTFE being constant. Bubble nucleation and behavior were observed by using high-speed camera. The results showed that the heat transfer performance of surfaces with PTFE hydrophobic circle spot is better than superhydrophilic surface in overall condition. Furthermore, the heat transfer performance decreases under subcooled condition for all surfaces. Increase in peripheral length of hydrophobic-spot enhances the heat transfer performance.
\end{abstract}

Key words: PTFE Hydrophobic, $\mathrm{TiO}_{2}$-Coated, Bubble Nucleation, Photographic, Subcooling and Saturated

\section{Introduction}

Nucleate boiling is widely used in a variety of industrial processes because of its highly efficient heat transfer performance, where energy transfer is dominated by latent heat of evaporation. As widely known, heat transfer characteristic in nucleate pool boiling depends on number of active nucleation sites and wall superheating ${ }^{(1)}$. To increase active nucleation sites, two methods of surface modification are commonly used as the enhancement technique; one is to control wettability and the other is roughness ${ }^{(2)}$. From viewpoint of cooling technique, it is important not only to enhance boiling heat transfer but also to control bubble nucleation. Such an example is a looped heat pipe for electronic package cooling. For a reliable cooling, stable nucleate boiling has to occur in the evaporator of the looped heat pipe with low surface superheating. If there is a large overshoot of superheating for boiling incipience, the electronic package will be damaged. To solve this problem, control of surface wettability is a promising technique.

In general, a surface wettability can be divided into two terms, depending on contact angle, i.e. hydrophobic and hydrophilic. Bubble nucleation occurs at very low superheating

*Received 25 Jan., 2013 (No. 13-0025) [DOI: 10.1299/jtst.8.294]

Copyright $\odot 2013$ by JSME 
on a hydrophobic surface and it has better heat transfer coefficient (HTC) at low heat flux ${ }^{(3)}$, (4). Conversely, on a hydrophilic surface the incipience of bubble nucleation is at high superheating and critical heat flux (CHF) increases to almost twice ${ }^{(5)}$. Previous studies on the effect of surface wettability have revealed that the hydrophilicity raises the CHF and the hydrophobicity promotes bubble nucleation. Therefore, a combination of superhydrophilicity and hydrophobicity will provide an ideal boiling surface. We have been developing such a surface (mixed-wattability) by making use of PTFE and $\mathrm{TiO}_{2}$ coating.

Interestingly, some previous studies have reported that a significant enhancement can be achieved in boiling heat transfer by using a mixed-wettability surface ${ }^{(6),(7),(8)}$. Suroto et al. ${ }^{(6)}$ has used a surface with PTFE hydrophobic dots on copper surface. However, the question of how the PTFE hydrophobic-spot contributes to enhancing a boiling heat transfer is still in question. The latest study ${ }^{(7)}$ shows that the bubble always be divided into two parts. One part departs and other part remains on the hydrophobic-spot. The remaining part of the bubble is able to create a chain of bubble generation without any having waiting time. However, how the remaining part can grow and what factors influence the growth are still obscure. The results obtained by Wang et al. ${ }^{(9)}$ showed that the preferred bubble formation occurs at the edge of PTFE hydrophobic spot because the edge presented has a higher roughness than central region. As is well known the increase in surface roughness would increase the number of nucleation sites per unit area ${ }^{(10)}$ and resultingly a boiling heat transfer ${ }^{(11)}$.

In the present study, we try to complement the previous study of mixed-wettability surface on boiling heat transfer performance ${ }^{(6)}$. The present study focuses on the effects of the edge (micro structures and length) of the PTFE hydrophobic-spot and degree of subcooling. A high-speed camera was used to capture bubble dynamics and the sequence of the process leading to a bubble dome formation was disclosed. Based on the photographic image, we reveal what factors are the most influential in the mechanism of boiling heat transfer enhancement.

\section{Nomenclature}

$\begin{array}{ll}h_{l v} & : \text { latent heat }(\mathrm{J} / \mathrm{kg}) \\ p_{v} & : \text { vapor pressure }\left(\mathrm{N} / \mathrm{m}^{2}\right) \\ p_{g} & : \text { sum of partial pressure non-condensing natural gas }\left(\mathrm{N} / \mathrm{m}^{2}\right) \\ q & : \text { heat flux }\left(\mathrm{kW} / \mathrm{m}^{2}\right) \\ R_{a} & : \text { arithmetic average roughness }(\mu \mathrm{m}) \\ R_{c} & : \text { radius bubble curvature }(\mu \mathrm{m}) \\ T_{\text {sat }} & : \text { saturated temperature }\left({ }^{\circ} \mathrm{C}\right) \\ T_{w} & : \text { surface temperature }\left({ }^{\circ} \mathrm{C}\right) \\ T_{\infty} & : \text { bulk temperature }\left({ }^{\circ} \mathrm{C}\right) \\ v_{l v} & : \text { difference of specific volume }\left(\mathrm{m}^{3} / \mathrm{kg}\right) \\ \Delta T_{\text {sat }} & :\left(T_{w}-T_{\text {sat }}\right)(\mathrm{K}) \\ \Delta T_{\infty} & :\left(T_{w}-T_{\infty}\right)(\mathrm{K}) \\ \Delta T_{\text {sub }} & : \text { subcooling }(\mathrm{K}) \\ \alpha=q / \Delta T_{\infty} & : \text { heat transfer coefficient }\left(\mathrm{kW} / \mathrm{m}^{2} \mathrm{~K}\right) \\ \sigma & : \text { surface tension }(\mathrm{N} / \mathrm{m}) \\ \phi & : \text { diameter of hydrophobic-spot }(\mathrm{mm})\end{array}$




\section{Experimental apparatus and surface fabrication}

Figures 1 and 2 show the schematic diagram of the experimental apparatus, heater block and the photographs of the heat transfer surfaces, respectively. The experimental apparatus is the same as the one used in the previous study ${ }^{(6)}$ with some modifications to the heat transfer surface and the heat transfer block. The heat transfer block is a copper cylinder of $30 \mathrm{~mm}$ in diameter. The detail of the experimental apparatus is shown in the Fig. 1. The heat transfer block (2) faces upwards and is fitted with a fin near its edge to prevent bubble nucleation there, as shown in Fig. 2(a). The experiment was conducted with liquid subcooling of $0-20 \mathrm{~K}$. Test conditions are maintained by monitoring thermocouples (4). The heat flux and surface temperature were measured by three K-type thermocouples (3) which were embedded in the heater block. Two Sheathed-Heaters (SWP1070) with maximum power of $700 \mathrm{~W}$ are used to provide the adjustable input power. The hydrodynamic behaviors of the bubbles were recorded using a high speed camera (5) (Phantom v.4.3 and lens AF NIKOR

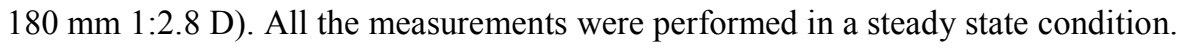

Figure 2 (a) and (b) is the detail of the heater block and heating surface. Figure 2(a) shows a component, dimension and position of every component on the heater block. The heated area is $30 \mathrm{~mm}$ in diameter where the PTFE dots are patterned. Four heating surfaces were fabricated for the present experiment: (1) First, to obtain references data of boiling performance we used a superhydrophilic surface which is made from polished copper and then coated with $\mathrm{TiO}_{2}$ layer using sputtering method. This $\mathrm{TiO}_{2}$ coating has a thickness of $1.15 \mu \mathrm{m}$, and when the surface is exposed to UV light for more than 12 hours it becomes superhydrophilic. The outlook of this surface is shown in the upper left of Fig. 2(b)(1). The second, we have made three mixed-wettability surfaces. These are the $\mathrm{TiO}_{2}$-coated surface with PTFE circle dots.

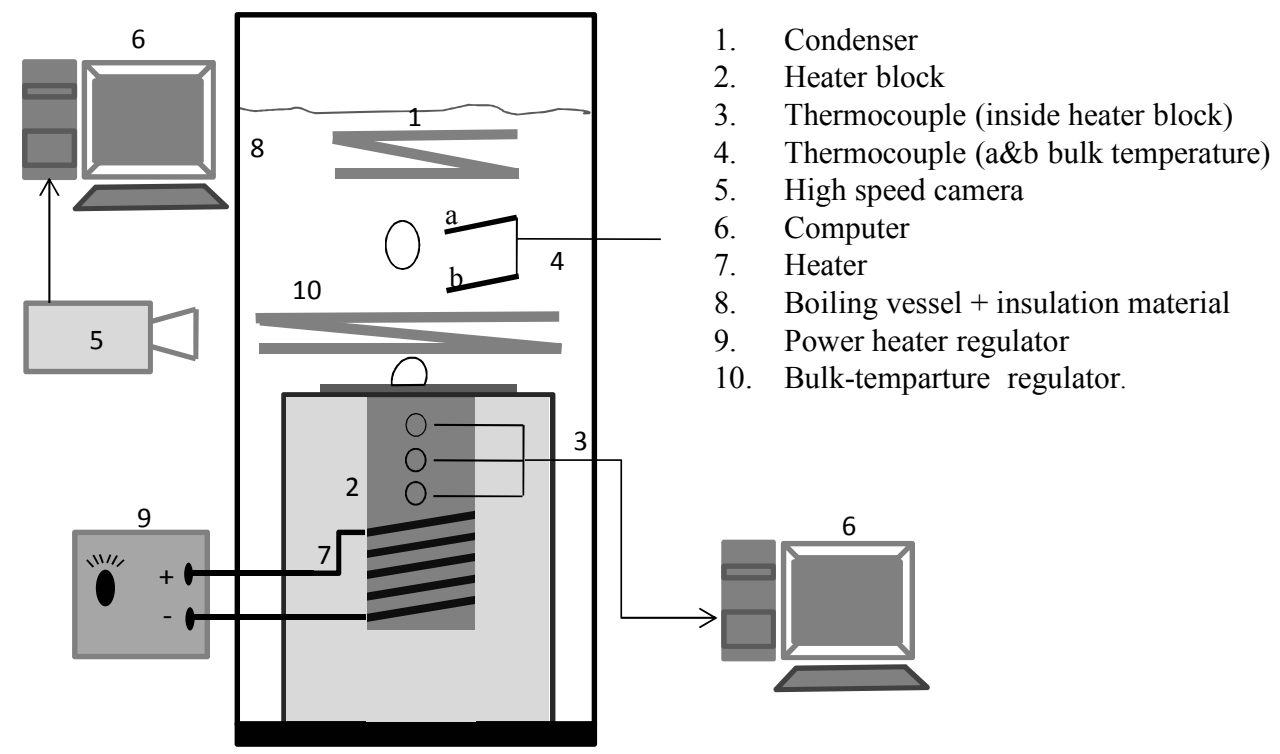

Fig. 1 Schematic diagram of experimental apparatus 


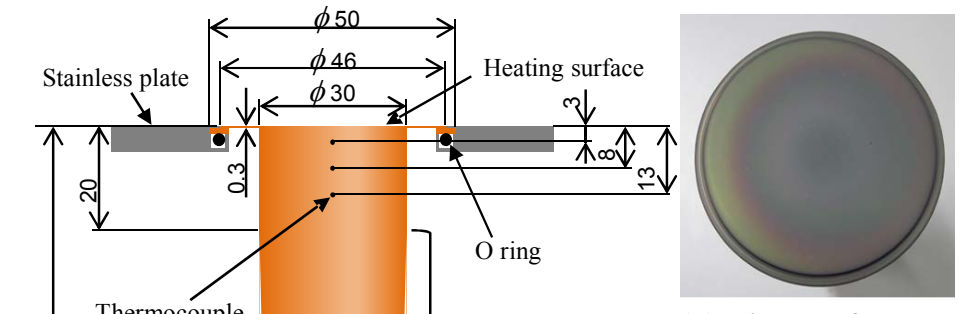

(1) $\mathrm{TiO}_{2}$ surface

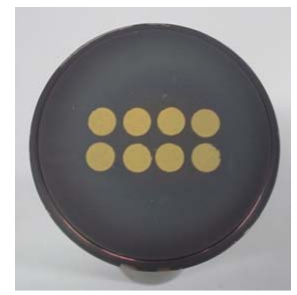

(3) PTFE $\phi=6 \mathrm{~mm}$

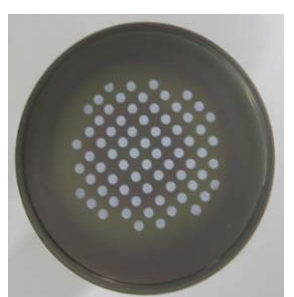

(2) PTFE $\phi=2 \mathrm{~mm}$

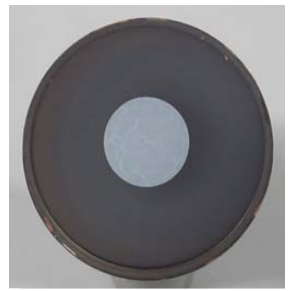

(4) PTFE $\phi=17 \mathrm{~mm}$

Total area of the PTFE region is same in these three mixed-wettability surfaces (2), (3) and (4)

(a) Heat transfer block

(b) Heating surface

Fig. 2 Heat transfer block (a) and Heating surfaces (b): superhydrophilic surface (1) and mixed-wettability surface (2)-(4)

As shown in Fig. 2(b)(2)-(4), the diameters of PTFE dots are 2, 6, and $17 \mathrm{~mm}$, respectively, and the number of these dots are 72,8 and 1, respectively, so that the total area of PTFE region is the same in these three surfaces. The contact angle is $120^{\circ}-127^{\circ}$, whereas the remaining $\mathrm{TiO}_{2}$ region has its contact angle of $0^{\circ}$. In these surfaces two materials with different roughness and wettability are mixed.

The superheat is evaluated at the $\mathrm{TiO}_{2}$ surface because the $\mathrm{TiO}_{2}$ layer is $1.15 \mu \mathrm{m}$ in thickness and its thermal resistance can be neglected in the moderate heat flux region. The present study focuses on the low heat flux region and therefore, the temperature drop caused by the PTFE layer is estimated roughly as $1.3 \%$ at low heat flux near ONB and $11.9 \%$ at maximum heat flux.

\section{Experimental results and discussion}

As mentioned earlier, we are interested in developing an ideal boiling surface which generates boiling at low surface superheating and has higher CHF. The present study focuses on bubble nucleation and heat transfer performance in the low heat flux region. For this purpose, we prepared four surfaces, as shown in Fig. 2, and experiments have been conducted at saturated and subcooled conditions. Prior to the heat transfer measurement, the air trapped on the PTFE hydrophobic-spot surface was evacuated by a vacuum pump. Water is then fed into the vessel and subsequently boiled for 30 minutes for degassing. Heat flux was designed for nucleate pool boiling from low to the intermediate level. Discussion will be divided in two parts, photographic analysis and nucleate boiling heat transfer performance.

\subsection{Photographic analysis}

\subsubsection{Effect of edge on onset of bubble nucleation (ONB)}

One interesting phenomenon regarding bubble nucleation from the mixed-wettability surface is that the bubble is always generated and grows alongside the edge of PTFE hydrophobic-spot. This is in accordance with the previous result by Wang et al. ${ }^{(9)}$. Figure 3 
shows that the bubble nucleation is initiated from the edge of the PTFE hydrophobic-spot for mixed-wettability surfaces. It is known that hydrophobicity decreases the superheating at the onset of bubble nucleation (ONB). Nevertheless, since bubble nucleation occurs always from the edge of the PTFE hydrophobic-spot, hydrophobicity seems not the only factor.

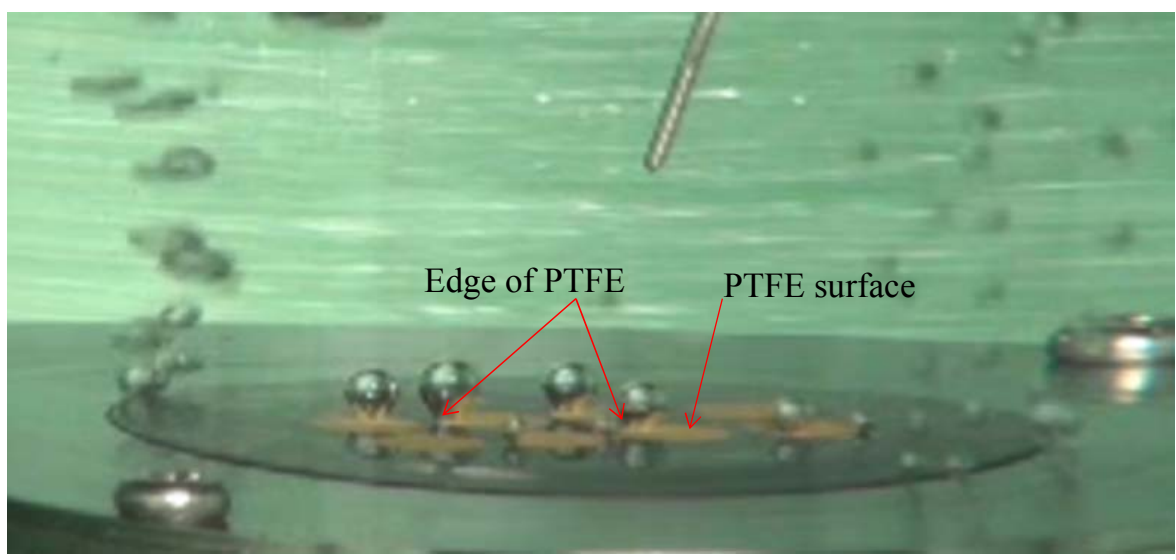

$q=9.5 \mathrm{~kW} / \mathrm{m}^{2} ; \Delta T_{\text {sat }}=2.1 \mathrm{~K} ; T_{\infty}=100{ }^{\circ} \mathrm{C}$

Fig. 3 Bubble incipience initiated from the edge of the hydrophobic-spot for $\phi=6 \mathrm{~mm}$

It is interesting to investigate the micro-geometry structure of this PTFE spot and its relationship with ONB. Figure 4(a) shows the 3D view of the micro-geometry structure region of a part of PTFE spot with $\phi=6 \mathrm{~mm}$ and 4 (c) is a line of the height curve along the red line on the Fig. 4(b)(1)-(2). Numbering in Fig. 4(c)(1) to indicate the region of the materials where (1) $\mathrm{TiO}_{2}$ and (2) edge of the PTFE surface, respectively. It is obvious from on the Fig. 4(a) and (c)(1)-(2) that more cavities can be observed on the edge of the PTFE hydrophobic-spot compared with the $\mathrm{TiO}_{2}$ region and the center of the PTFE spot. It can be also indicated by higher roughness value $\left(R_{a}=3.51 \mu \mathrm{m}\right)$ compared with $\mathrm{TiO}_{2}$ surface $\left(R_{a}=0.125 \mu \mathrm{m}\right)$ and the center of the PTFE spot $\left(R_{a}=0.930 \mu \mathrm{m}\right)$, as shown in Fig. 4(c)(1)-(2). Unfortunately a relationship between roughness and cavity size are still remain unclear until present. However, the latest study ${ }^{(12)}$ showed that the depth of the active cavities increases as the RMS roughness increases which probably means a higher volume of vapor being trapped. On the other hand, the increase in the radius of nanobubble curvature will decrease the superheat for bubble nucleation ${ }^{(13)}$. In the micro-scale hydrophobic-spot ${ }^{(7)}$, the superheat required for ONB is dependent on the diameter of the hydrophobic-spot. However, in the present case, the size of the hydrophobic-spot does not affect the superheat for ONB and Fig. 5 shows that phenomenon. Figure 5 indicates nucleate boiling curves which do not contain the data in the natural convection region. This means that the most left data in the figure represent the boiling incipience. It is obvious from the figure that the superheating for ONB are the same with the data for the same subcooling and slightly increase with the increase in subcooling. 


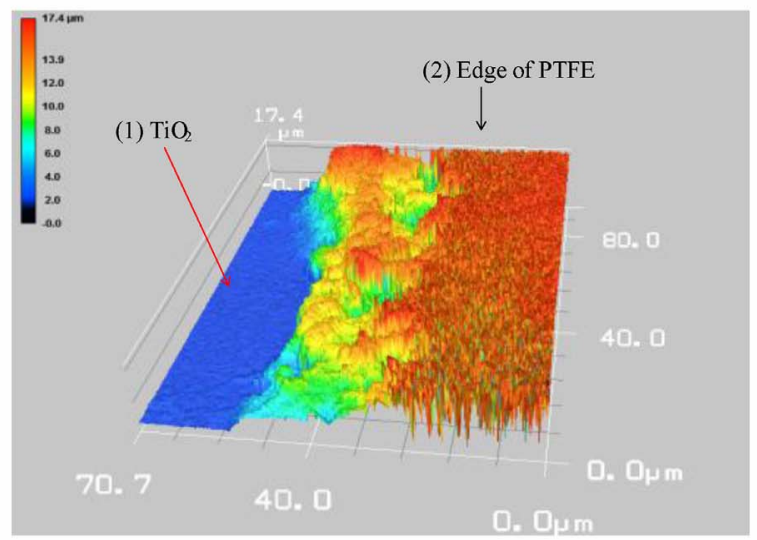

(a) 3D micro structure of edge of the PTFE

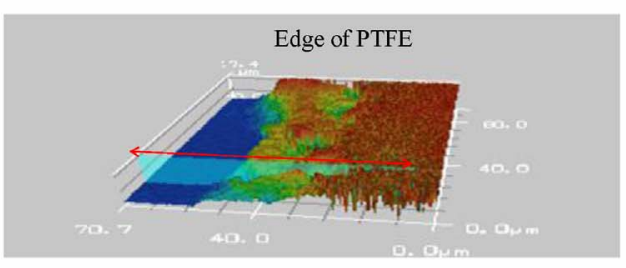

(1) Edge of PTFE

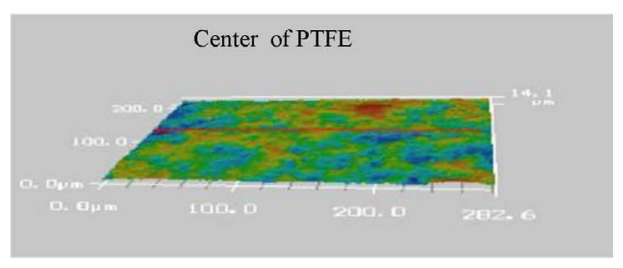

(2) Center of PTFE

(b) Line of roughness measurement
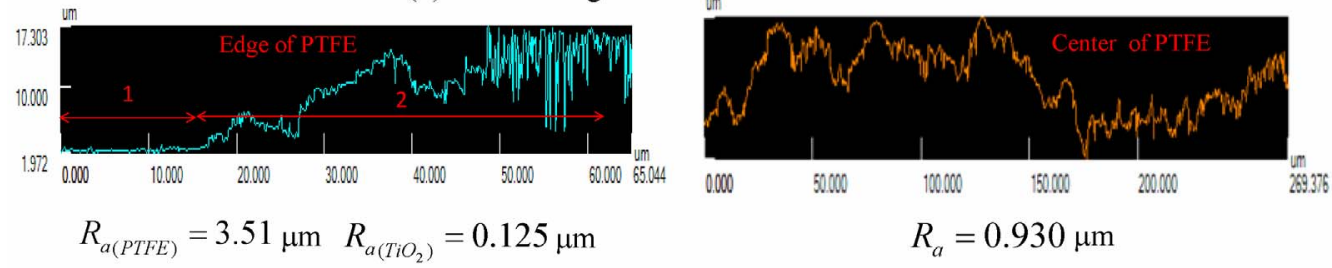

(c) Line of height curve along red line

Fig. 4 3D structures of the PTFE hydrophobic-spot and its height curve

\subsubsection{Effect of subcooling on ONB and bubble behavior}

Increase in degree of subcooling causes decreases in superheated liquid thickness ${ }^{(14)}$. The superheated liquid layer is required for bubble growth ${ }^{(15)}$. Furthermore, $\mathrm{Hsu}^{(16)}$ proposed a model in which the incipience of boiling and the size of active cavity, $R_{c}$, are strongly dependent upon the limiting thickness of the superheated liquid layer, $\delta$, while the decrease in $\delta$ causes the decrease in $R_{c}$. Howel and Siegle ${ }^{(17)}$ stated in their model that if $R_{c}$ $<\delta$, the cavity will be activated and the bubble grows over the cavity. However, if $R_{c}>\delta$, the bubble will collapse due to condensation because the bubble surface is surrounded by subcooled water. In the classical-preexisting theory, the relationship between $R_{c}$ and $\Delta T_{\text {sat }}$ is given by the following equation :

$$
\Delta T_{s a t}=\frac{T_{s a t} v_{l v}}{h_{l v}}\left(\frac{2 \sigma}{R_{c}}-p_{g}\right)
$$

where $R_{c}$ and $p_{g}$ are radius of bubble curvature and partial pressure of non-condensible gas, 
respectively. Therefore, the decrease in $R_{c}$ causes the increase in $\Delta T_{\text {sat }}$ and, consequently, the ONB will require higher superheating. Surprisingly, the increase in subcooling results in the shift of $\Delta T_{\text {sat }}$ to left of the graph, namely the negative values, as shown in Fig. 5 except for the $\mathrm{TiO}_{2}$ surface, while the $\Delta T_{\text {sat }}$ for the ONB does not change regardless of the size of PTFE hydrophobic dots. The ONB of the $\mathrm{TiO}_{2}$ surface occurs at $\Delta T_{\text {sat }}=8-9 \mathrm{~K}$. At the present experiments, the degree of superheating at ONB for $\phi=6 \mathrm{~mm}$ and at subcooled 20 $\mathrm{K}$ was $-4.17 \mathrm{~K}\left(T_{w}=95.64{ }^{\circ} \mathrm{C}\right)$ and the corresponding vapor pressure, $p_{v}$, is $0.0878 \mathrm{MPa}$. Regarding the negative values of $\Delta T_{\text {sat }}$ for subcooled condition, we guess that this is the effect of non-condensable gas. As mentioned earlier, we always have a degassing process prior to each experiment. However, the experimental system is connected to atmosphere in the upper part of boiling vessel and the solution of air into test fluid can not completely be avoided. Actually we observed that from time to time the bubble departed from the surface and rose upward without condensing until it reached the liquid surface. In addition, the contact angle of the PTFE surface is around $127^{\circ}$ and for this higher contact angle the curvature in the cavity in equation (1) becomes negative. Therefore, if the effect of dissolved air is negligibly small as reported by Muller et al. ${ }^{(19)}$, the vapor nuclei inside the PTFE cavity can exist even below the atmospheric boiling point. We hope that the reason why we had negative $\Delta T_{\text {sat }}$ at the ONB will be disclosed through the future study.

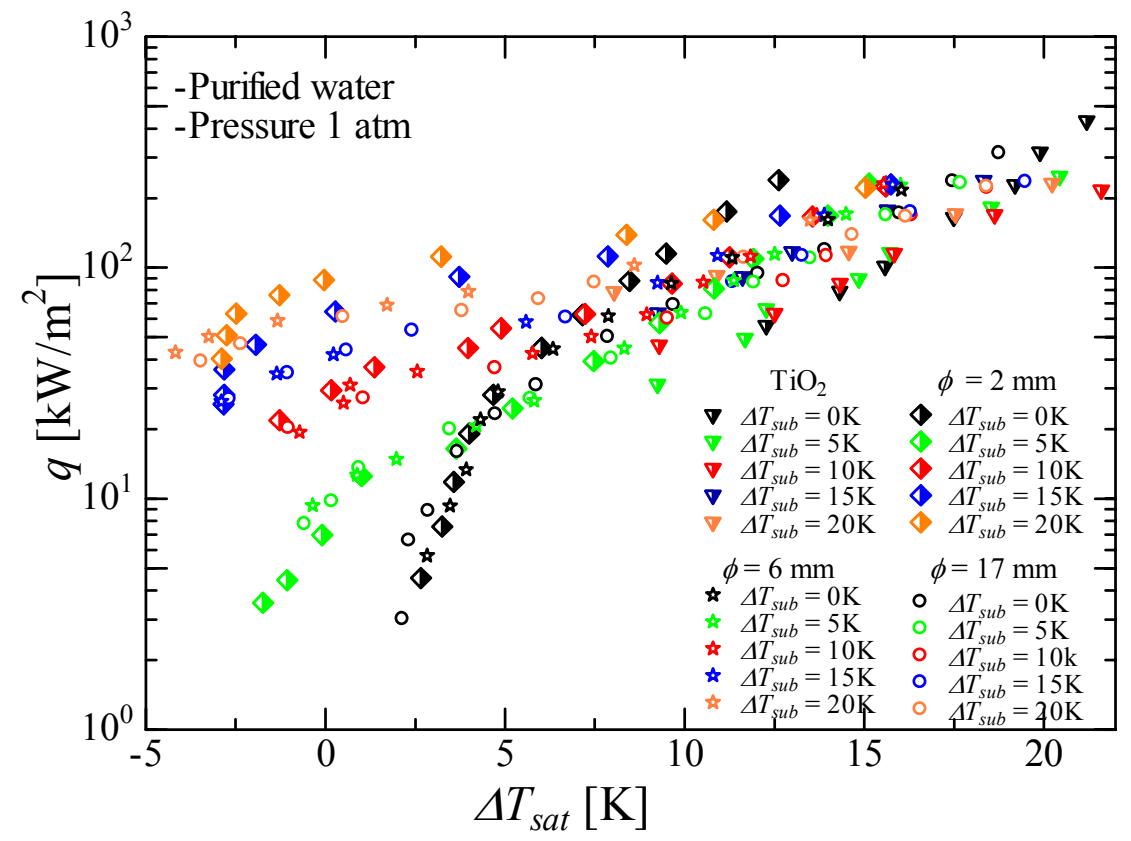

Fig. 5 Boiling curve of superhydrophilic and mixed-wettability surface for $\phi=2-17 \mathrm{~mm}$ at saturated and subcooled conditions

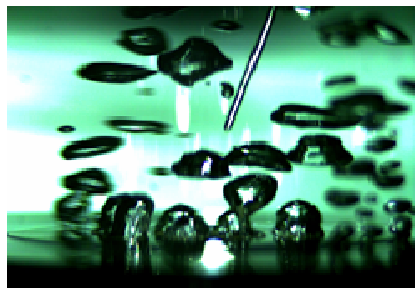

(a) $q=55 \mathrm{~kW} / \mathrm{m}^{2}$; $\Delta T_{\infty}=7.5 \mathrm{~K}$; $\Delta T_{\text {sub }}=0 \mathrm{~K}$

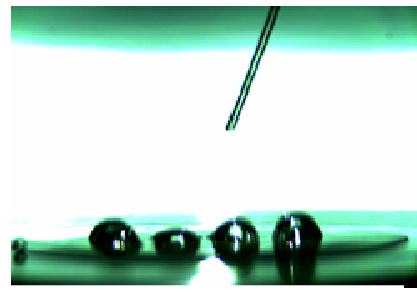

(b) $q=44.9 \mathrm{~kW} / \mathrm{m}^{2}$; $\Delta T_{\infty}=13.9 \mathrm{~K}$ $\Delta T_{s u b}=5 \mathrm{~K}$

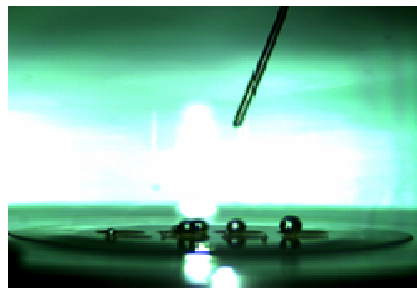

(c) $q=35 \mathrm{~kW} / \mathrm{m}^{2}$ $\Delta T_{\infty}=14.7 \mathrm{~K}$; $\Delta T_{\text {sub }}=20 \mathrm{~K}$

Fig. 6 Bubble behavior on the PTFE hydrophobic-spot $(\phi=6 \mathrm{~mm})$ for various subcooling 
Figure 6 shows the image of the bubble behavior at saturated and subcooled conditions. As shown in Fig. 6(a), the bubble behavior looks like a normal saturated pool boiling. However, at subcooled condition, the bubble shows a unique behavior. It does not depart for a while and oscillates up and down on the PTFE hydrophobic-spot, as shown in Fig. 6(b) and (c). We conjectured that it occurs due to imbalance between condensation and evaporation. Condensation occurs when the bubble surface contacts with the liquid where its temperature is below saturated condition. Meanwhile, when the condensation occurs, at the edge of PTFE hydrophobic-spot the bubbles seeds which contain vapor and a small amount of non-condensable gas is supplied continuously. The bubble volume increases due to the accumulation of non-condensable gas in the main bubble ${ }^{(18)}$. From time to time, the bubble departure is observed. The bubble shrinks somewhat during rising upward, but it reaches to liquid surface. This is one evidence that the bubble contains non-condensable gas inside.

\subsubsection{Effect of hydrophobic-spot size on bubble behavior}

Figure 7 shows bubble behaviors on the PTFE hydrophobic-spot. Previous research ${ }^{(7)}$ has reported the detailed explanation of bubble behavior on micro-scale hydrophobic-spot. However, at the present study the surface pattern was designed in the millimeter-size. Figure 3 shows the bubble incipience is initiated from the edge of the hydrophobic-spot. As the heat flux increase, the number of nucleation site on the PTFE edge increases. Furthermore, discrete bubbles alongside the edge of the hydrophobic-spot will coalesce with neighbors, and then become one larger bubble with a hemispherical shape which covers the whole PTFE hydrophobic-spot. An interesting fact is that as shown in Fig. 7, when the bubble departs, a part of the bubble remains on the PTFE hydrophobic-spot. This means that there is no waiting time in the bubble departure cycle. The PTFE hydrophobic-spot is always covered with vapor and this vapor grows to vapor dome and separate into two parts as shown in Fig. 7(a). One departs upward while the other remains on the surface and works as a nucleus (Fig. 7(b)) of the next bubble generation. As mentioned in the previous section the edge of the PTFE hydrophobic-spot may contribute significantly to bubble nucleation because the largest cavity exists there. It is still unclear how remaining bubble on the PTFE spot helps to maintain continuous bubble generation and departure. Therefore, the present research explores this case by analyzing Fig. 7 (a)-(f). Figure 7(b), as indicated by the red arrow, the remaining bubble on the PTFE hydrophobic-spot can be observed and in this period the PTFE hydrophobic-spot is constantly covered with the vapor. Next bubble starts to grow from this remaining vapor as seen in Fig. 7(c)-(f).

In this period, the growth mechanism of the remaining part of the bubble is still obscure. There are two possibilities for this. First possibility might be that the vapor inside the bubble expands due to heat conduction through the vapor and radiation from the PTFE hydrophobic surface. However, this is unlikely because the thermal conductivity of PTFE hydrophobic is too low and temperature of hydrophobic surface is not high enough for the radiation effect to be considered. The second possibility is that the bubble seed is supplied from the peripheral boundary between PTFE hydrophobic-spot and superhydrophilic region, as indicated by the red arrow and as shown in Fig. 7(b), (e), and (f). The bubbles grow on the boundary between two superhydrophilic and hydrophobic regions. The base of 
the bubble would shrink when it faces on the superhydrophilic surface and conversely, the bubble would be expanded if it is on the surface of the PTFE hydrophobic-spot. Furthermore, the bubble would merge with other bubble seed to increase the volume.

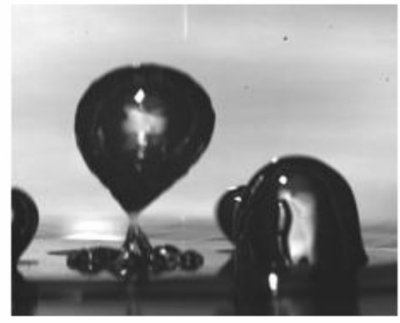

(a) $0 \mathrm{~s}$

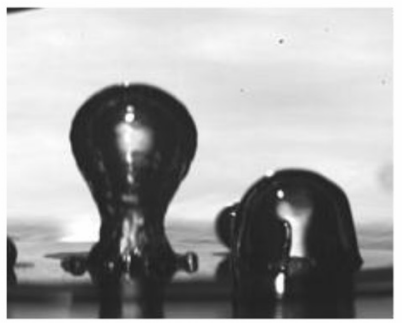

(d) $0.311 \mathrm{~s}$

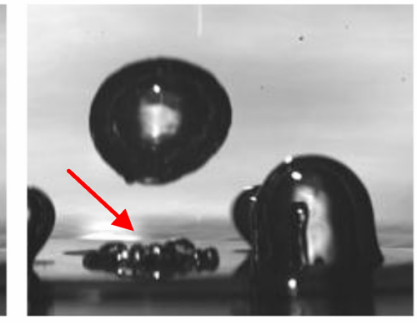

(b) $0.002 \mathrm{~s}$

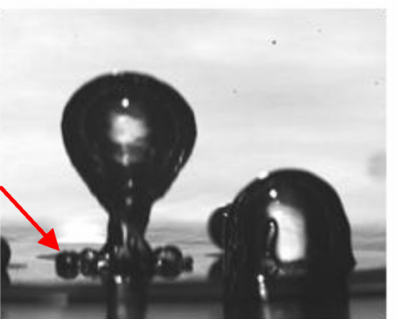

(e) $0.315 \mathrm{~s}$

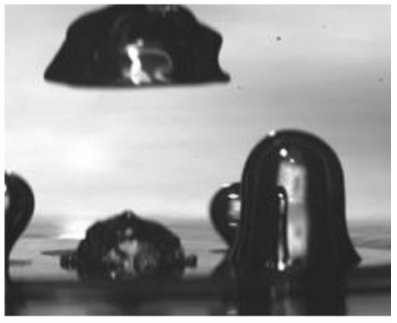

(c) $0.019 \mathrm{~s}$

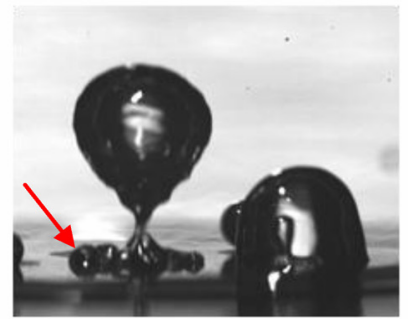

(f) $0.316 \mathrm{~s}$

Fig. 7 Bubble behavior on the hydrophobic-spot, mixed-wettability surface $\phi=6 \mathrm{~mm}$, $q=13.4 \mathrm{~kW} / \mathrm{m}^{2}, \Delta T_{\text {sat }}=3.9 \mathrm{~K}, T_{\infty}=100{ }^{\circ} \mathrm{C}$

\subsection{Nucleate boiling heat transfer performance}

\subsubsection{Effect of subcooling}

The boiling heat transfer coefficient, $\alpha$, is influenced by the number of nucleation sites, bubble departure frequency and size. Muller et al. ${ }^{(19)}$ and Jung et al. ${ }^{(20)}$ used $\Delta T_{\infty}=\left(T_{w}-T_{\infty}\right)$ as the temperature difference to $\alpha$ and we use the same definition. Figure 8(a)-(d) shows $\alpha$ versus $q$ curves for four surfaces. Figure 8(a) is for the superhydrophilic surface as the reference and Fig. 8(b)-(d) are for the mixed-wettability surfaces which have PTFE dot diameter of 2, 6, and $17 \mathrm{~mm}$, respectively. Every sample surface was tested under the liquid subcooling ranging from $0-20 \mathrm{~K}$. The results show that the heat transfer performance decreases for all mixed-wettability surfaces at subccoled condition, however it is still better than that of superhydrophilic surface. As mentioned in section 3.1.2, the subcooling causes delays of $\mathrm{ONB}$ and the reduction of $\Delta T_{\text {sat }}$ at $\mathrm{ONB}$ due to non-condensable gas.

Obviously, the increase in degree of subcooling reduces the amount of heat transferred by latent heat and this is in accordance with the previous result by Rainey ${ }^{(21)}$. Despite the fact that the increase in degree of subbcooling increases a natural convection effect, it gives a little contribution to the total heat transferred to the liquid. As shown in Fig. 8(b)-(d), the boiling heat transfer from all mixed-wettability surfaces show the same trend especially at low heat flux for subcooling of 5-20 K. Conversely, when heat flux was raised at a certain value, the heat transfer coefficient began to separate depending on subcooling. However, the heat transfer coefficient for mixed-wettability surface is still remains worse than that of saturated condition. The discrepancy of the heat transfer coefficient of mixed-wettability surface will varies depending on the diameter of hydrophobic-spot. As shown in the Fig. 8, the value of heat flux at which the heat transfer coefficient begins separate depending on subcooling are $55 \mathrm{~kW} / \mathrm{m}^{2}$ for $\phi=17 \mathrm{~mm}, 70 \mathrm{~kW} / \mathrm{m}^{2}$ for $\phi=6 \mathrm{~mm}$, and $100 \mathrm{~kW} / \mathrm{m}^{2}$ for $\phi=$ 
$2 \mathrm{~mm}$, respectively.

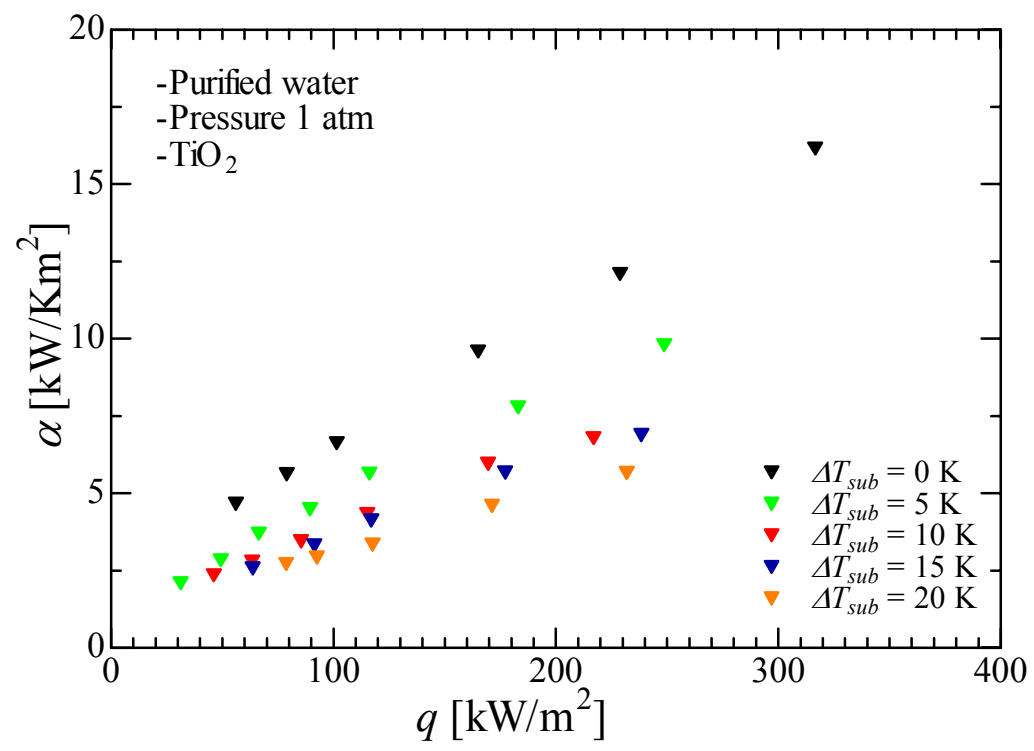

(a) Superhydrophilic $\left(\mathrm{TiO}_{2}\right)$ surface

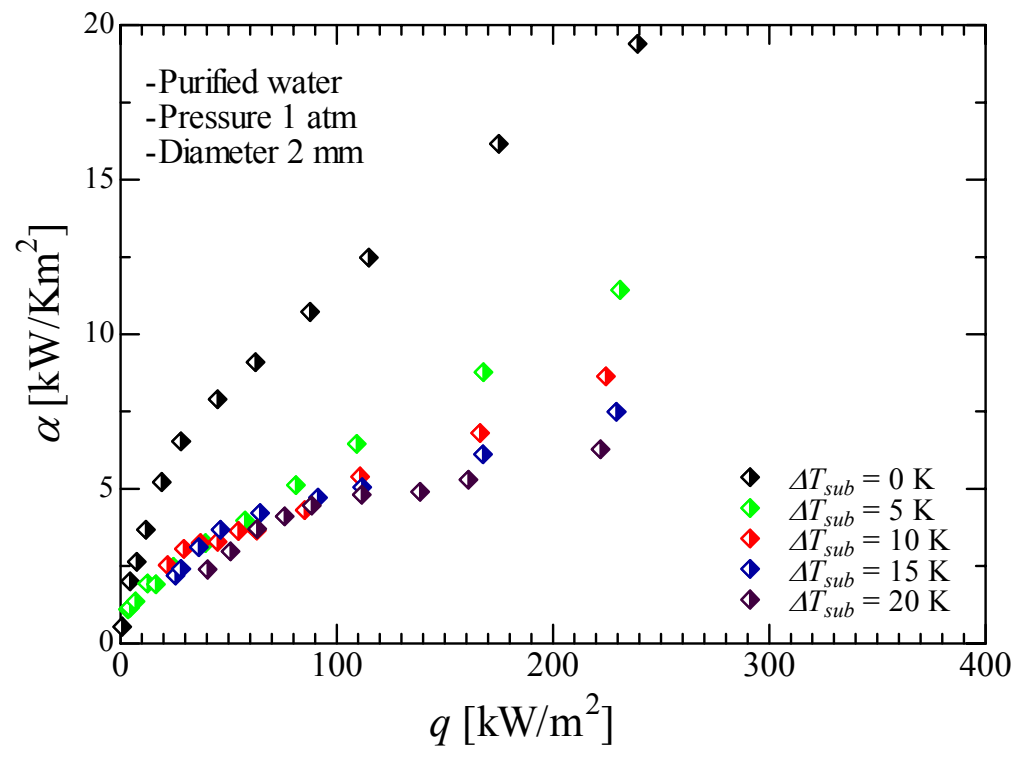

(b) Mixed wettability surface $\phi=2 \mathrm{~mm}$ 


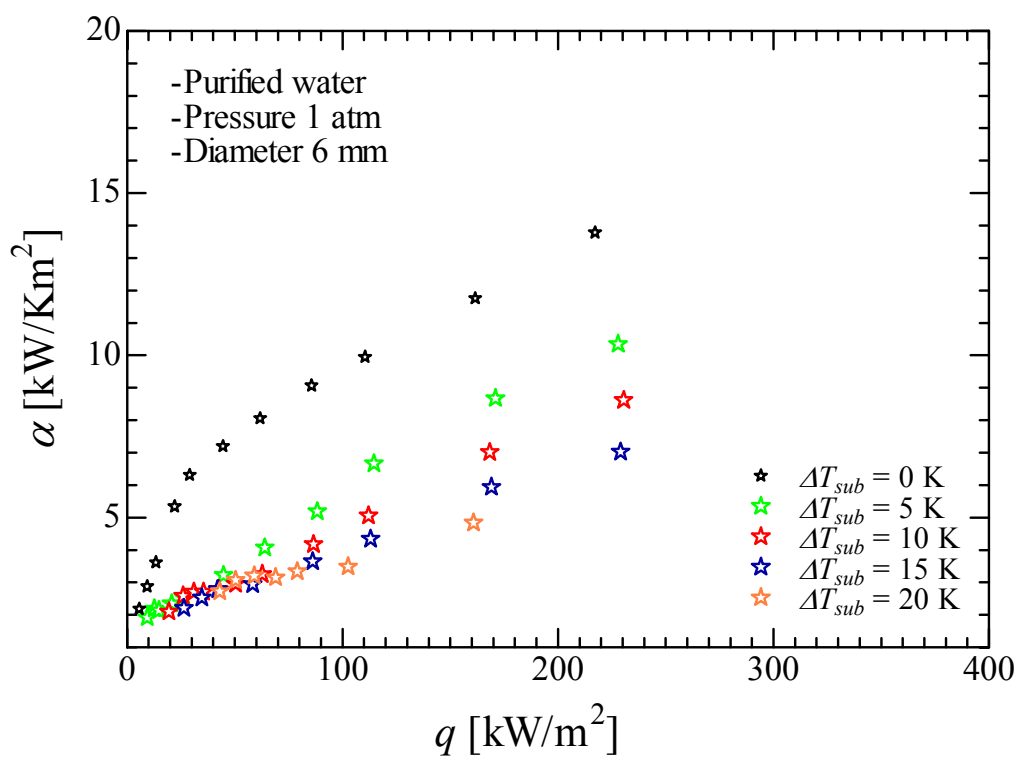

(c) Mixed wettability surface $\phi=6 \mathrm{~mm}$

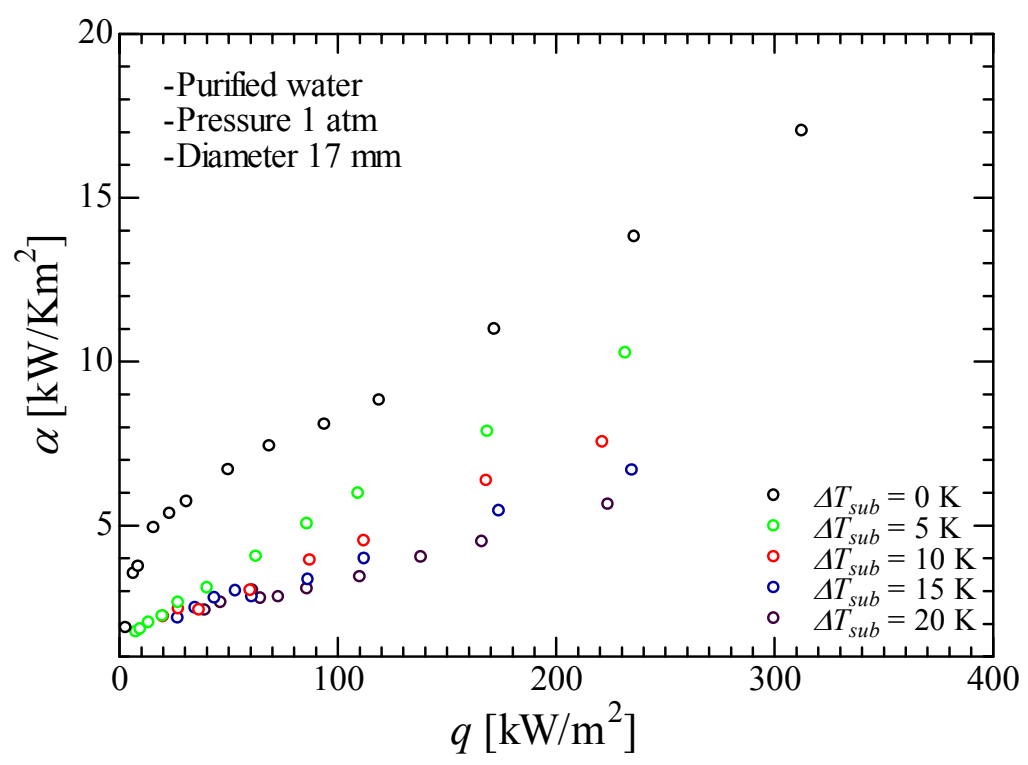

(d) Mixed wettability surface $\phi=17 \mathrm{~mm}$

Fig. 8 Effect of subcooling on nucleate boiling heat transfer of superhydrophilic and mixed-wettability surfaces

\subsubsection{Effect of pattern design}

In this section, discussion is made on the effect of peripheral length of PTFE hydrophobic-spot on boiling heat transfer performance. Figure 9 shows a comparison of heat transfer coefficient for all sample surfaces. The results show that the increase in peripheral length of PTFE hydrophobic-spot, increases boiling heat transfer performance. Under the present experimental conditions, it was found that the surface which has 72 PTFE hydrophobic-spots with $\phi=2 \mathrm{~mm}$ was the best among all mixed-wettability surfaces except for subcooling $5 \mathrm{~K}$. However, we found a something unique characteristic. That is, the data started to separate at low heat flux and separation continues at higher heat flux as shown in Fig. 10(b)-(d). At present, the reason of this phenomenon is not clear. This phenomenon seems to occur in a particular range of subcooling, in the present case at 
$10-20 \mathrm{~K}$ and the difference becomes larger with the increase in subcooling. For subcooling $10 \mathrm{~K}$, see Fig. 10(b), at high heat flux, hydrophobic-spot $2 \mathrm{~mm}$ and $6 \mathrm{~mm}$ are coincided. However, for subcooling 15 K, Fig. 10(c) and 20 K, Fig. 10(d), the separation occurs until the high heat flux and hydrophobic-spot $2 \mathrm{~mm}$ is superior to those conditions.

The reduction of the size of the hydrophobic-spot causes two effects : one is the increase in the peripheral length of the PTFE hydrophobic-spot and the other is that the distance between adjacent two nucleation sites becomes narrower. Consequently, the smaller PTFE hydrophobic-spot has the increase in the surface roughness and also has a number of active nucleation sites.

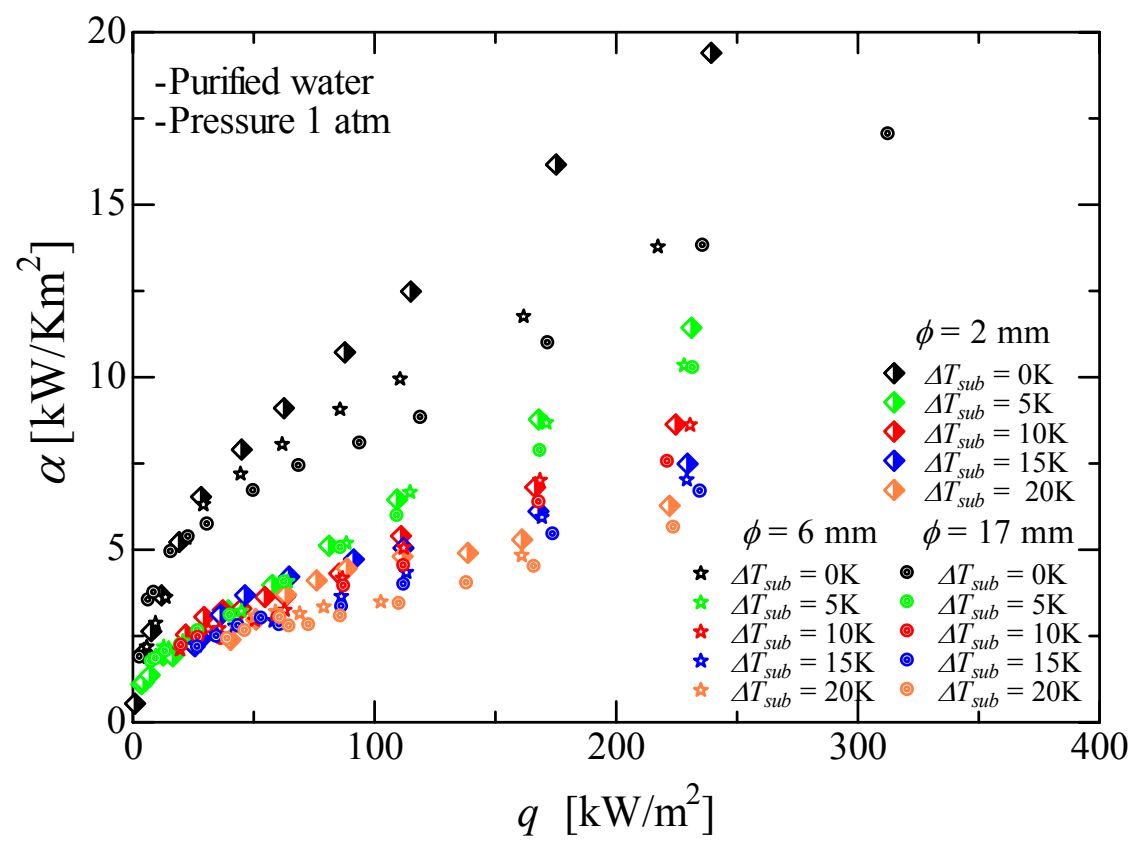

Fig. 9 Effect of hydrophobic-spot size on nucleate boiling heat transfer for various subcooling

The mixed-wettability surface with $\phi=2 \mathrm{~mm}$ has a peripheral length of hydrophobic-spot by 8.5 times longer than that with $\phi=17 \mathrm{~mm}$ and therefore, the surface with $\phi=2 \mathrm{~mm}$ showed the best performance among all mixed-wettability surfaces.

\section{Conclusion}

Experimental investigation has been conducted on the effects of subcooling and the peripheral length of PTFE hydrophobic-spot for mixed-wettability surface on nucleate boiling heat transfer performance. The results are summarized as follows:

1. The mixed-wettability surfaces show better boiling heat transfer performance compared with the $\mathrm{TiO}_{2}$ superhydrophilic surface at saturated and subcooled conditions.

2. An increase in the peripheral length of the hydrophobic-spot total with the total area of the hydrophobic region being constant enhances the boiling heat transfer performance at saturated and subcooled condition. However, at subcooled condition, the enhancement was observed at a certain range of heat fluxes. 


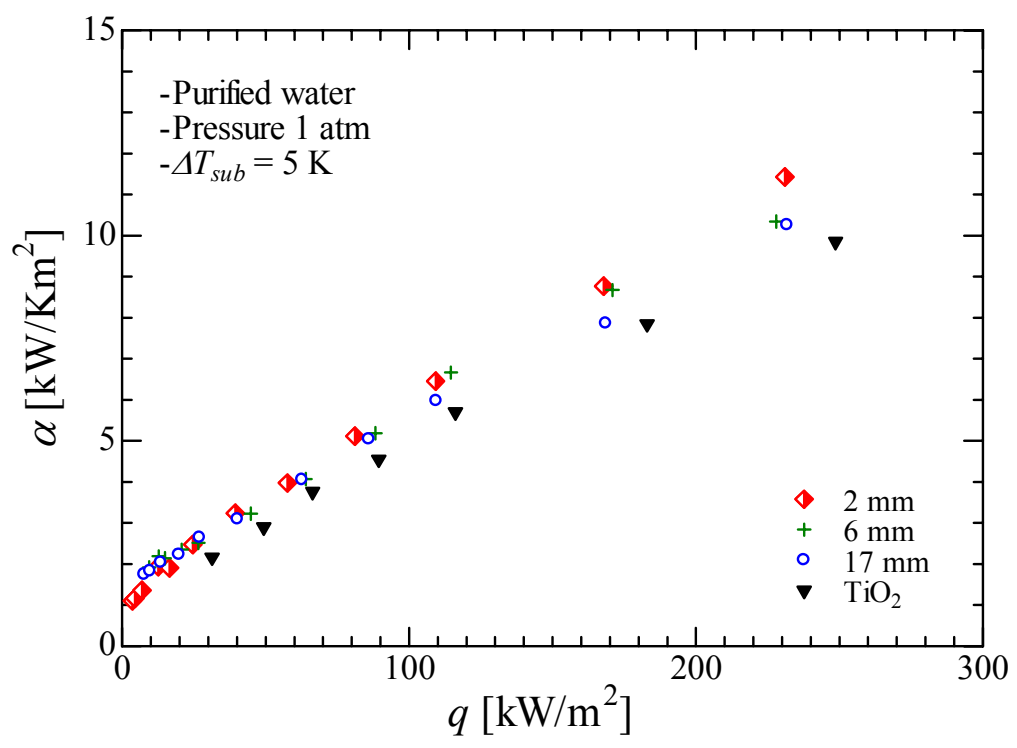

(a) Subcooling $5 \mathrm{~K}$

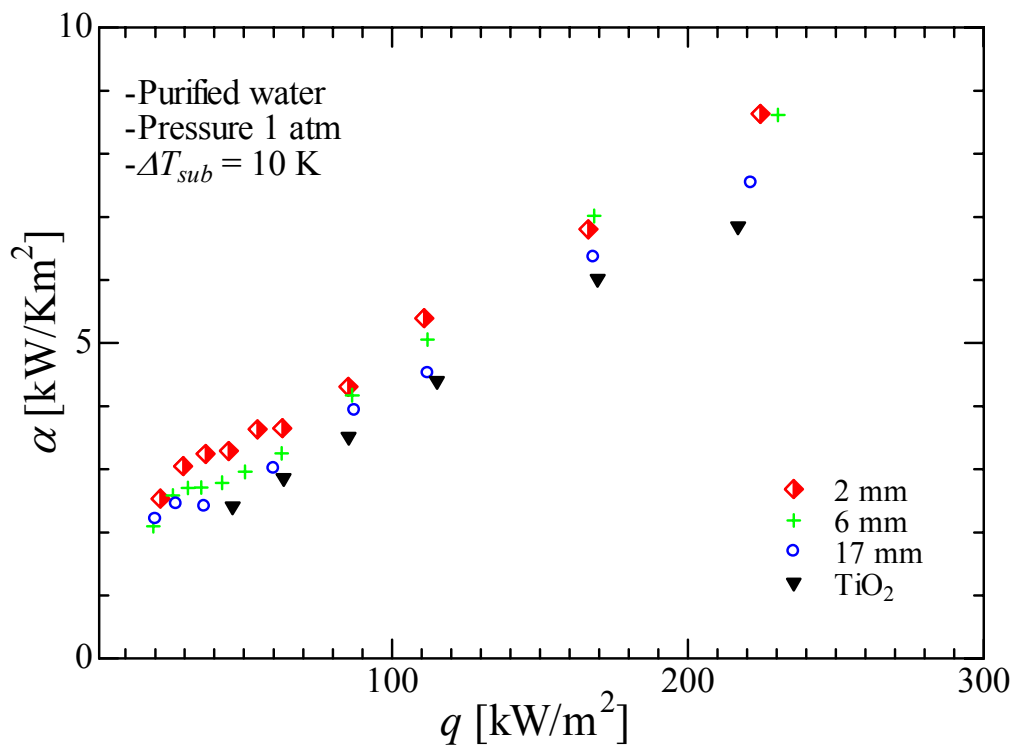

(b) Subcooling $10 \mathrm{~K}$

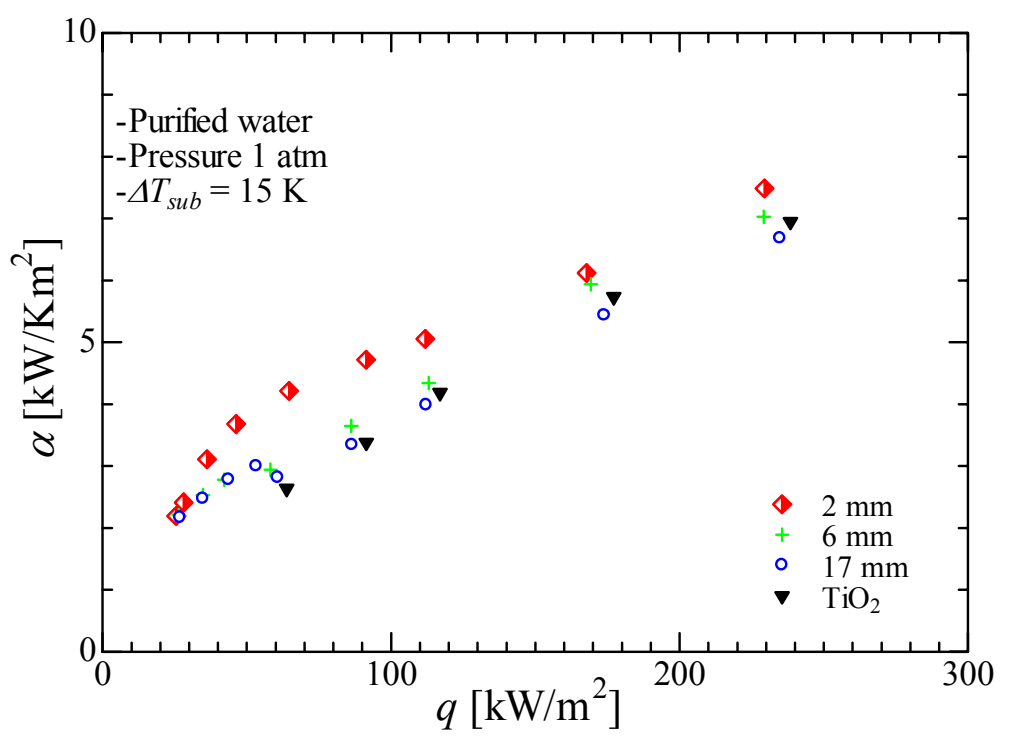

(c) Subcooling $15 \mathrm{~K}$ 


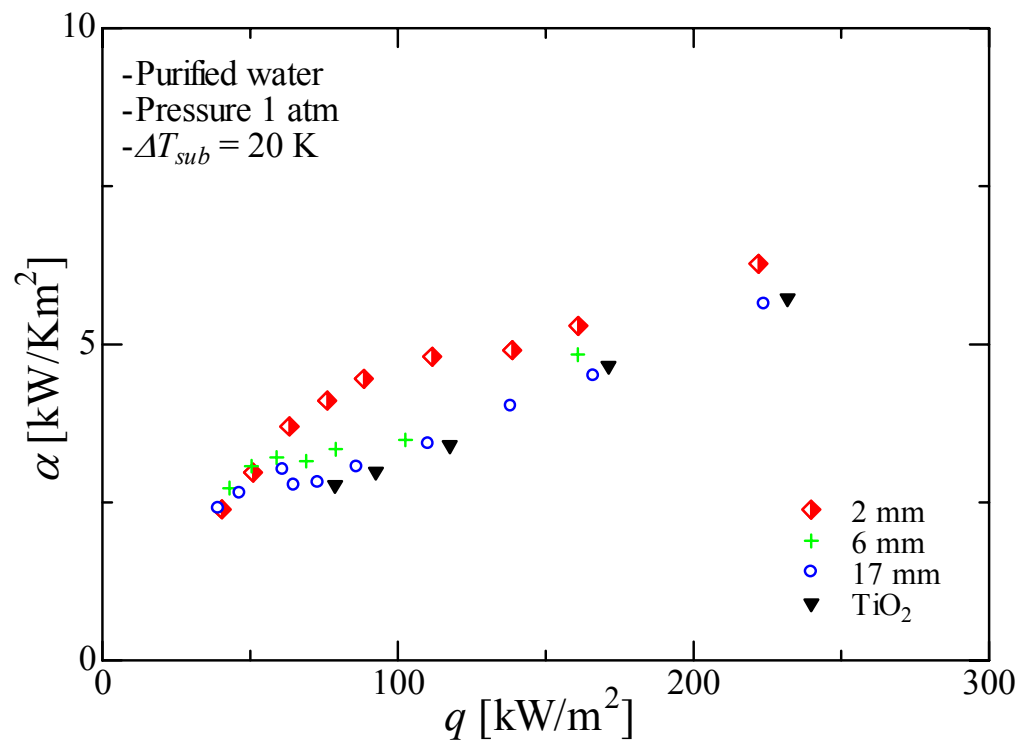

(d) Subcooling $20 \mathrm{~K}$

Fig. 10 Nucleate boiling heat transfer at subcooled condition

3. Subcooling reduces the performance of boiling heat transfer, whereas the physical properties (i.e. wettability and roughness) of the surface does not change the performance.

4. It was found from the photographic image of the bubble behaviors that the bubble departs continuously without any waiting time from the PTFE hydrophobic-spot. Under high subcooling condition and low high flux, the bubble stays all the time on the PTFE hydrophobic-spot and oscillates up and down.

\section{Acknowledgement}

Scholarship provided by Indonesia Government for Doctoral degree at Kyushu University, Japan is greatly acknowledged by Bambang Joko Suroto, an academic staff of Lampung University, Indonesia.

\section{References}

1. Tong, L.S., and Tang, Y.S., Boiling Heat Transfer and two-Phase Flow, (1997) TAYLOR \& FANCOIS.

2. Hibiki, T., and Ishii, M., Active Nucleation Site Density in Boiling System, International Journal of Heat and Mass Transfer 46 (2003) 2587-2601.

3. Takata, Y., Hidaka, S., and Uraguchi, T., Boiling Feature on a Super Water-Repellent Surface, Heat Transfer Engineering 27 (2006) 25-30.

4. Phan, H.T., Caney, N., Marty, P., Colasson, S., and Gavillet, J., Surface Wettability Control by Nanocoating: The Effects on Pool Boiling Heat Transfer and Nucleation Mechanism, International Journal of Heat and Mass Transfer 52 ( 2009) 5459-5471.

5. Takata, Y., Hidaka, S., Cao, J.M., Nakamura, T., Yamamoto, H., Masuda, M., and Ito, T., Effect of Surface Wettability on Boiling and Evaporation, Energy 30 (2005) 209-220.

6. Suroto B.J., Tashiro, M., Kakitani, T., Hidaka, S., Kohno, M., and Takata, Y., Enhancement of Heat Transfer in Pool boiling by using a patterned hydrophobic 
coating on polished copper surface, Proceeding of The Eighth KSME-JSME, Thermal and Fluids Engineering Conference GST03-003 (2012).

7. Jo, H., Ahn, H.S., Kang, S.H., and Kim, M.H., A Study of Nucleate Boiling Heat Transfer on Hydrophilic, Hydrophobic and Heterogeneous Wetting Surfaces, International Journal of Heat and Mass Transfer 54 (2011) 5643-5652.

8. Betz, A.R., Xu, J., Qiu, H., and Attinger, D., Do Surfaces With Mixed Hydrophilic and Hydrophobic Areas Enhance Pool Boiling?, Appl. Phys. Lett. 97141909 (2010).

9. Wang, X., Zhao, S., Wang, H., and Pan, T., Bubble Formation on Superhydrophobic-Micropatterned Copper Surfaces, Applied Thermal Engineering 35 (2012) 112-119.

10. Benyamin, R.J., and Balakrishnan, A.R., Nucleation Site Density in Pool Boiling of Saturated Pure Liquid: Effect of Surface Microroughness and Surface and Liquid Physical Properties, Experimental Thermal and Fluid Science 15 (1997) 32-42.

11. Kang, M.G., Effect of Surface Roughness on Pool Boiling Heat Transfer, International Journal of Heat and Mass Transfer 43 (2000) 4073-4085.

12. Mpholo, M., Mathaba, T., and Bau, H.H., A 2D analysis of Surface Roughness for Prediction of Boiling Incipience, International Journal of Heat and Mass Transfer 53 (2010) 1313-1318.

13. Nam, Y., and Ju, Y. S., Bubble nucleation on hydrophobic Islands Provide Evidence to Anomalously High Contact Angle of Nanobubbles, Appl. Phys. Lett. 93103115 (2008).

14. Wiebe, J.R., and Judd, R.L., Superheat Layer Thickness Measurements in Saturated and Subcooled Nucleate Boiling, Journal of Heat Transfer 93 (1971) 455-461.

15. Han, C., and Griffith, P., The mechanism of Heat Transfer in Nucleate Pool Boiling-Part I: Bubble Initiaton, Growth and Departure, International Journal of Heat and Mass Transfer 8 (1965) 887-904.

16. Hsu, Y.Y., On the Size Range of Active Nucleation Cavities on Heating Surface, Journal of Heat Transfer 84 ( 1962) 207-213.

17. Howell, J.R., and Siegel, R., Incipience, Growth, and Detachment of Boiling Bubbles in Saturated Water From Artificial Nucleation Sites of Known Geometry and Size, Proceedings of the Third international Heat Transfers Conference 1966.

18. Marek, R., and Straub, J., The Origin of Thermocapillary Convection in Subcooled Nucleate Pool Boiling, International Journal of Heat and Mass Transfer 44 (2001) 619-632.

19. Müller-Steinhagen, H., Epstein, N., and Watkinson, A.P., Effect of Dissolved Gases on Subcooled Flow Boiling Heat Transfer, Chemical Engineering and Processing: Process Intensification, 23 (1988) 115-124.

20. Jung, J.Y., and Kwak, H.Y., Effect of Surface Condition on Boiling Heat Transfer From Silicon Chip with Submicron-Scale Roughness, International Journal of Heat and Mass Transfer 49 (2006) 4543-4551.

21. Rainey, K.N., You, S.M., and Lee, S., Effect of Pressure, Subcooling, and Dissolved Gas on Pool Boiling Heat Transfer From Microporous Surfaces in FC-72, Journal of Heat Transfer 125 (2003) 75-83. 